\title{
Alternate Double Single Track Lines
}

\author{
Paola Moraga \\ Assistant Professor, Pontificia Universidad Católica de Valparaíso, Chile \\ Zacarias Grande \\ Assistant Professor, University of Cantabria, Spain. \\ Enrique Castillo
}

Full Professor, University of Cantabria and Royal Academy of Engineering, Spain.

\section{SUMMARY}

The paper discusses the advantages and shortcomings of alternate double single track (ADST) lines with respect to double track lines for high speed lines. ADST lines consists of sequences of double and single track segments optimally selected in order to reduce the construction and maintenance costs of railway lines and to optimize the timetables used to satisfy a given demand. The single tracks are selected to coincide with expensive segments (tunnels and viaducts) and the double tracks are chosen to coincide with flat areas and only where they are necessary. At the same time, departure times are adjusted for trains to cross at the cheap double track segments. This alternative can be used for new lines and also for existing conventional lines where some new tracks are to be constructed to reduce travel time (increase speed). The ADST proposal is illustrated with some examples of both types (new lines and where conventional lines exist), including the Palencia-Santander, the Santiago-Valparaíso-Viña del Mar and the Dublin-Belfast lines, where very important reductions $(90 \%)$ are obtained, especially where a railway infrastructure already exist.

\section{INTRODUCTION}

High-speed railway technology, which is expanding all over the world, produces important benefits, such as important speed increases and passenger time savings, increase in safety and comfort, punctuality improvement and generation of new economical and social activities. However, the associated costs are very high and decisions to invest in this technology have not always been based on a serious profitability analysis. As a result, there have been non satisfactory and negative social impact investment returns. Consequently, alternative solutions to the classical double-track solution have appeared. One of them is the "Alternate Double-Single Track (ADST) solution" (see Castillo et al. (2009, 2011, 2015a, 2016b). However, these new solutions require on the one side the capacity and timetable optimization of planned or existing railway lines, which are very difficult and complex problems (see Carey (1994), Higgins et al. (1996), Caprara et al. (2002)), and on the other side a probabilistic safety analysis (see Castillo et al. $(2016 \mathrm{a}, \mathrm{c})$ ) to guarantee the adequate safety level.

Timetable optimization has played an important role in the existing literature on railway management (timetabling and traffic control). Some examples are the work of Caprara et al. 
(2007) who provide a state-of-the-art review on general railway optimization problems and the exhaustive analysis of existing optimization methods Cordeau et al. (1998). It consists of selecting the optimal time departures and arrivals of trains from and at stations so that safety constraints and user requirements are satisfied. This means that travel times must be minimized and all possible conflicts among running trains must be resolved. These problems have been dealt with in the literature by many authors (see, for example, Jia and Zhang (1993), Kraay and Harker (1995), Higgins et al. (1996), Sahin (1999), D’Ariano and Pranzo (2004); D'Ariano et al. (2007a), Carey and Lockwood (1995); Carey and Crawford (2007) or Burdett and Kozan (2010)) For a detailed and complete analysis of the timetable design principles see Pachl (2014).

This paper presents the application of the ADST methodology to several lines and aims to demonstrate that alternatives to the usual double track solution exist and that they are competitive.

This paper is organized as follows, In Section II the ADST lines are introduced and their advantages with respect to double and single-track lines are discussed. In section III some examples of applications, including the Palencia-Santander, the Dublin-Belfast and the Santiago-Valparaíso-Viña del Mar lines are given. Finally in section IV some conclusions are drawn.

\section{ALTERNATE DOUBLE-SINGLE TRACK (ADST) LINES.}

The ADST solution consists of using single tracks where the infrastructure is very expensive (tunnels and viaducts) and single-track where it is cheap. This means that trains are forced to cross at double tracked segments. For this to be possible, the time schedules of the conflicting trains must adequately be adjusted (with small corrections) with an optimization program so that no increase or very small increases of travel times are produced.

Other applications of the ASDT idea contemplate complementing existing conventional lines with the construction of new high-speed segments with the intention to reduce travel times and improve safety. The main advantage of this solution is that they are much less expensive than building new complete lines. It must be clarified that:

1) ADST lines are neither single-track nor double-track lines. They are new alternatives that must be designed taking into account the expected demand.

2) ADST lines capacity and travel times values are closer to those of double-track lines than to those of single-track lines. In fact for moderate demands they are almost identical.

3) ADST lines costs are closer to those of single-track lines than to those of doubletrack lines. The cost excess of an ADST line is not more than $15 \%$ of the corresponding single-track line cost. 
4) Construction costs are drastically reduced (up to $40 \%$ in new lines and $85 \%$ using existing lines) with respect to the costs of double-track lines.

5) Maintenance costs are also substantially reduced.

Since making a decision on single or double track segments and optimization of the associated timetables are not trivial problems, special software optimization programs are needed.

\section{EXAMPLES OF APPLICATIONS.}

In this section we illustrate the proposed methods by their application to several real cases.

\subsection{The Palencia-Santander line}

The Palencia-Santander line is a $217 \mathrm{~km}$ single-track line that belongs to the Spanish conventional railway network. For many years, Cantabrian politicians have petitioned to the central government for a high speed line to replace this line without success. A project approved several years ago permits the connection with a high speed double-track line of Palencia and Santander at a cost of $€ 3,329 \mathrm{M}$, which implies a travel time between Santander and Madrid of two and a half hours, but lacks financial support. In a previous paper (see Castillo et al. (2015a)) it has been shown how the use of the alternate double-single-track (ADST) approach, which combines single and double-track segments, permits reducing the construction costs to $€ 2,493 \mathrm{M}$. with very similar travel times, showing clearly that the ADST solution is an efficient alternative that should not be ignored. However, its cost was still too high to be a reasonable solution, due to the low associated traffic demands, because neither Santander nor Palencia are highly populated areas. This was the main reason why the central government did not provide financial support for the project during several years.

We presented another alternative to the Cantabrian government that allows reducing the cost to one tenth with an increase of half hour in travel time between Santander and Madrid. The upper plot in Figure 1 shows the optimized timetable and sequence of segments (four sections in double track and three in single track) for this proposal with associated cost of $€$ 336M. In order to guarantee robust timetable solutions, in addition to generous headways of 4 minutes, extra reductions of 5\% of the segment travel times and a margin of 3 minutes per $100 \mathrm{~km}$ have been considered in the analysis.

The proposal, which is illustrated in the lower plot, consists of:

- Build a new $90 \mathrm{~km}$ single-track from Palencia to Alar del Rey with no tunnels, where construction costs are low. This with the existing conventional track provides a mixed double-track segment.

- Complete the second track of the $27 \mathrm{~km}$ between Torrelavega and Santander, where the platform is already prepared, to include a second track at low cost. 

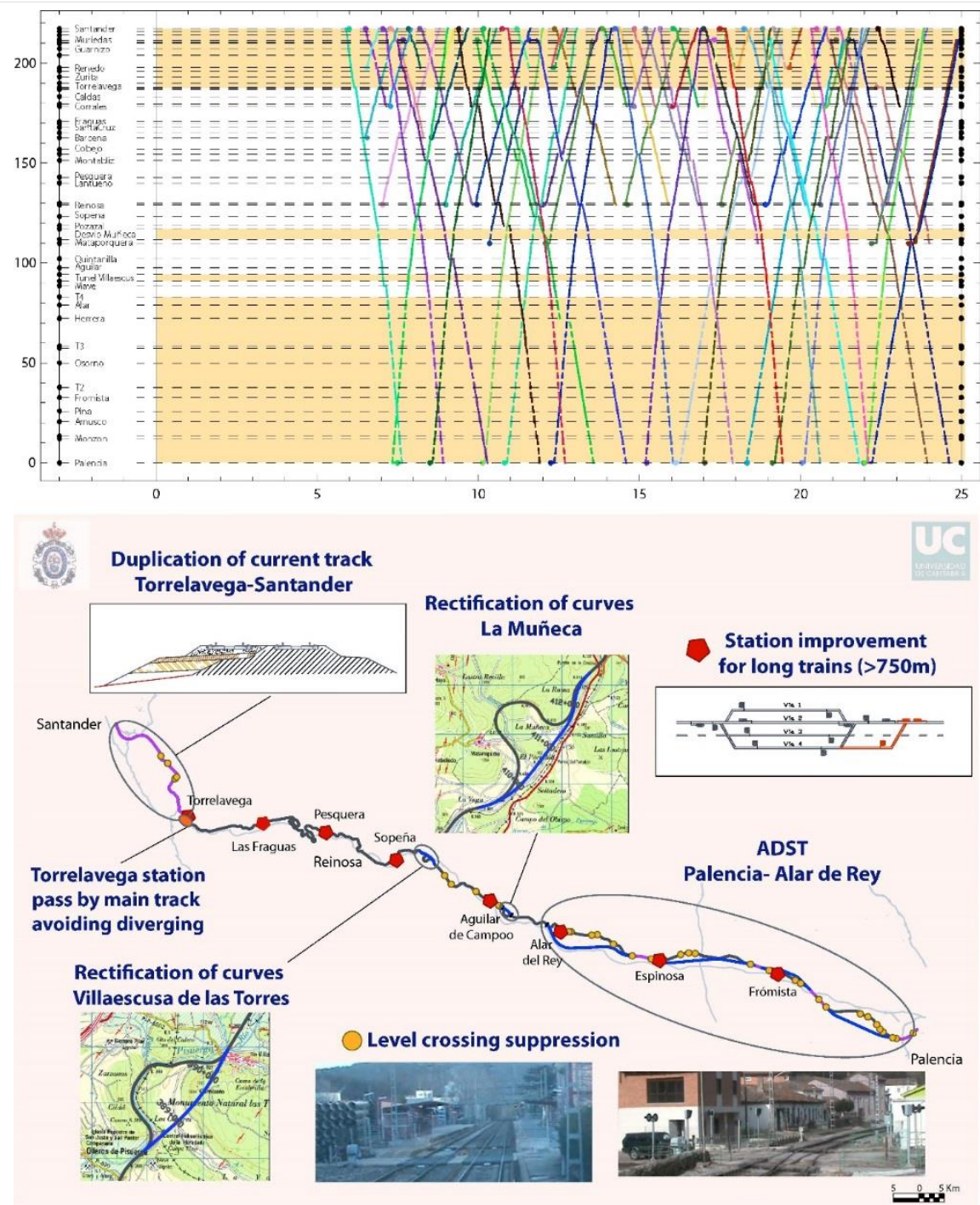

Figure 1 Optimized timetable proposal (upper plot) for the Palencia-Santander line leading to the proposed solution (lower plot).

- Rectify the curve at Villaescusa de las Torres by constructing a new tunnel at a favourable terrain.

- Rectify the curve at La MuÑeca building a new short viaduct with a simple foundation due to the existing adequate soil conditions.

- Remove the level crossings in order to permit an important speed increase at conventional segments.

- Increase track lengths at 8 stations in order to allow long freight trains $750 \mathrm{~m}$. to cross. This will produce an important development of the Santander port.

- The segments between Torrelavega and Alar del Rey contain curves of small radio, tunnels and, in some parts (from Torrelavega to Reinosa), a maximum slope. Consequently, it is an area where tunnels and viaducts are practically the only possible solution for building a high speed track. This implies a very high construction cost. Thus, these segments are kept as single-track, that is, no change in the line can be done at a reasonable cost. 


\subsection{The Dublin-Belfast line}

In the left plot of Figure 2 the trace of the current line between Dublin and Belfast (in blue color) together with their main stations are shown. Its length is $181 \mathrm{~km}$ and the current travel time is $2 \mathrm{~h}$ and $9 \mathrm{~min}$. In addition to offering 16 daily services between the two cities the network shares 312 daily services including the Dublin and Belfast commuter and freight transport services. In order to reduce the travel times we consider the following solutions:
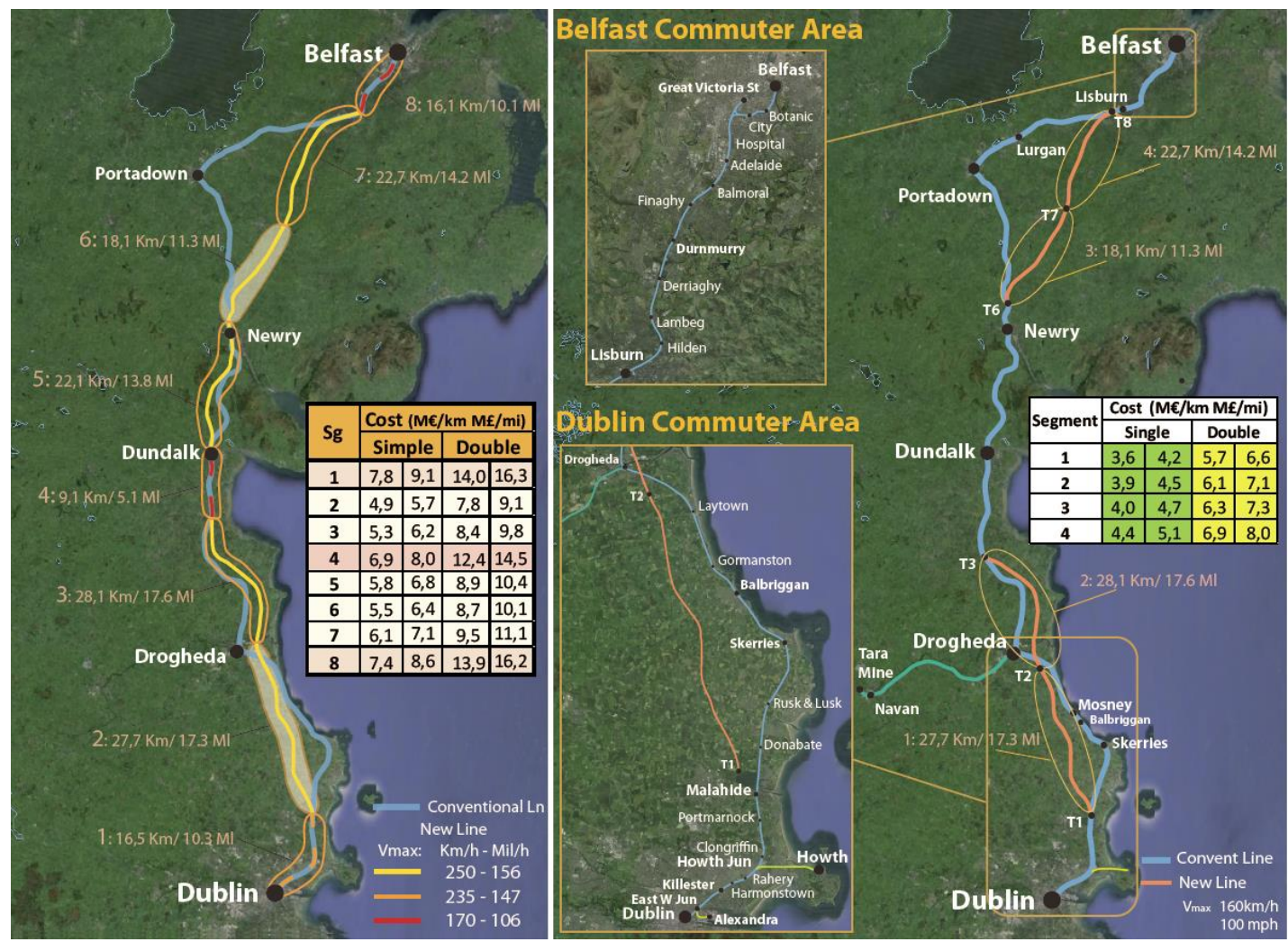

Figure 2 Left plot: Description of the actual (blue color) and the proposed ADST line solution showing the location of the eight segments and the two of them (in white color) that resulted in double-track. Right plot: Mixed high speed and conventional proposal.

\subsubsection{Double-track solution}

We propose a new $160.4 \mathrm{~km}$ double-track line with a reduction of $20 \mathrm{~km}$ with respect to the existing conventional line with only one intermediate stop at Dundalk shown in the left plot of Figure 2. This reduces the travel time between Dublin and Belfast to 50 minutes, which means 1 hour and 19 minutes reduction. The construction cost is $€ 1589.54 \mathrm{M}$. This will induce an increase in the number of the railway line users, new or coming from other conveyances, and will cause the appearance of new travel types.

\subsubsection{ADST solutions}

To optimize an ADST solution, the line has been partitioned in the eight segments shown in the left plot of Figure 2.

Figure 3 shows the results of the optimization program for five cases that range from single- 
track (case 1) to double-track (case 5) for all segments. The intermediate alternatives 2 to 4 consider one, two and three double-track segments, respectively. The percentages of singletrack length with respect to the total length, the construction costs, the percent savings with respect to the double-track solution construction cost and the resulting travel times for the different case combinations and the two routes, Dublin-Belfast and Dublin-Dundalk-Belfast after optimizing the timetables, and how they change when 32 daily services are considered instead of 16, complete the columns of the table. This implies a travel time of 50-51 min (Dublin-Belfast) and 54-55 min (Dublin-Dundalk-Belfast) considering 16 and 32 daily trains and a total capacity of 6.200 and 12.400 daily passengers.

\begin{tabular}{|c|c|c|c|c|c|c|c|c|c|c|c|c|}
\hline \multicolumn{6}{|c|}{ Segment } & \multicolumn{2}{|c|}{ Track Tipology HS } & \multicolumn{2}{|c|}{ Budget (Mill) } & \multirow{2}{*}{$\begin{array}{c}\text { Construction } \\
\text { Saving }\end{array}$} & \multicolumn{2}{|c|}{ TT $16 / 32 \mathrm{Sev}$ (min) } \\
\hline Case & \begin{tabular}{|l|l|l|}
1 & 2 \\
\end{tabular} & \begin{tabular}{|l|l|}
3 & \\
\end{tabular} & \begin{tabular}{l|l}
4 & 5 \\
\end{tabular} & 6 & \begin{tabular}{l|l}
78 & 8
\end{tabular} & Double & Simple & $M €$ & $M f$ & & D-B & D-Dk-B \\
\hline 1 & & & & & & $0 \%$ & $100 \%$ & 961,49 & 701,05 & $40 \%$ & $51 / 59$ & $58 / 70$ \\
\hline 2 & & & & & & $6 \%$ & $94 \%$ & $1.011,54$ & 737,54 & $36 \%$ & $51 / 52$ & $58 / 58$ \\
\hline 3 & & & & & & $29 \%$ & $71 \%$ & $1.099,74$ & 801,85 & $31 \%$ & $50 / 51$ & $54 / 55$ \\
\hline 4 & & & & & & $37 \%$ & $63 \%$ & $1.169,05$ & 852,39 & $26 \%$ & $50 / 50$ & $54 / 55$ \\
\hline 5 & & & & & & $100 \%$ & $0 \%$ & $1.589,54$ & 1158,98 & $0 \%$ & $50 / 50$ & $54 / 54$ \\
\hline
\end{tabular}

\section{Figure 3 ADST Cases for the analysis of the line Dublin-Belfast.}

Figure 3 shows the results of the optimization program for five cases that range from singletrack (case 1) to double-track (case 5) for all segments. The intermediate alternatives 2 to 4 consider one, two and three double-track segments, respectively. The percentages of singletrack length with respect to the total length, the construction costs, the percent savings with respect to the double-track solution construction cost and the resulting travel times for the different case combinations and the two routes, Dublin-Belfast and Dublin-Dundalk-Belfast after optimizing the timetables, and how they change when 32 daily services are considered instead of 16, complete the columns of the table. This implies a travel time of 50-51 min (Dublin-Belfast) and 54-55 min (Dublin-Dundalk-Belfast) considering 16 and 32 daily trains and a total capacity of 6.200 and 12.400 daily passengers.

After this analysis, it can be observed that the most convenient solution is Case 3 shown in Figure 2, that is, a 160,4 km high speed line composed of 2 double-track segments (in white color) and 6 single-track segments with a cost of $€ 1,099.74 \mathrm{M}$. The double track segments are located at the second and sixth segments starting from Dublin, and they will allow the services to cross at double-track segments.

\subsubsection{Proposal based on the existing network}

In this section an alternative that combines the existing conventional line with high speed segments of new construction is proposed. This proposal aims: (a) to provide a low cost connection between Dublin and Belfast in less than $1 \mathrm{~h} 30 \mathrm{~min}$., (b) to increase the capacity of the network, (c) to optimize the intermediate long distance link, (d) to promote the DublinBelfast commuter and business connections, and (e) to facilitate the cross border freight connection. 
We propose to build 4 new segments, as shown in the right plot of Figure 2 that is, between Donabate-Julianstown-Dromiskin (segments T1-T2 and T2-T3) and Newry-BanbridgeLisburn (segments T6-T7 and T7-T8). These new segments would operate to complement the current line, so that services (long distance link, commuter and freight traffic) could circulate using the current or new tracks, with no restriction.

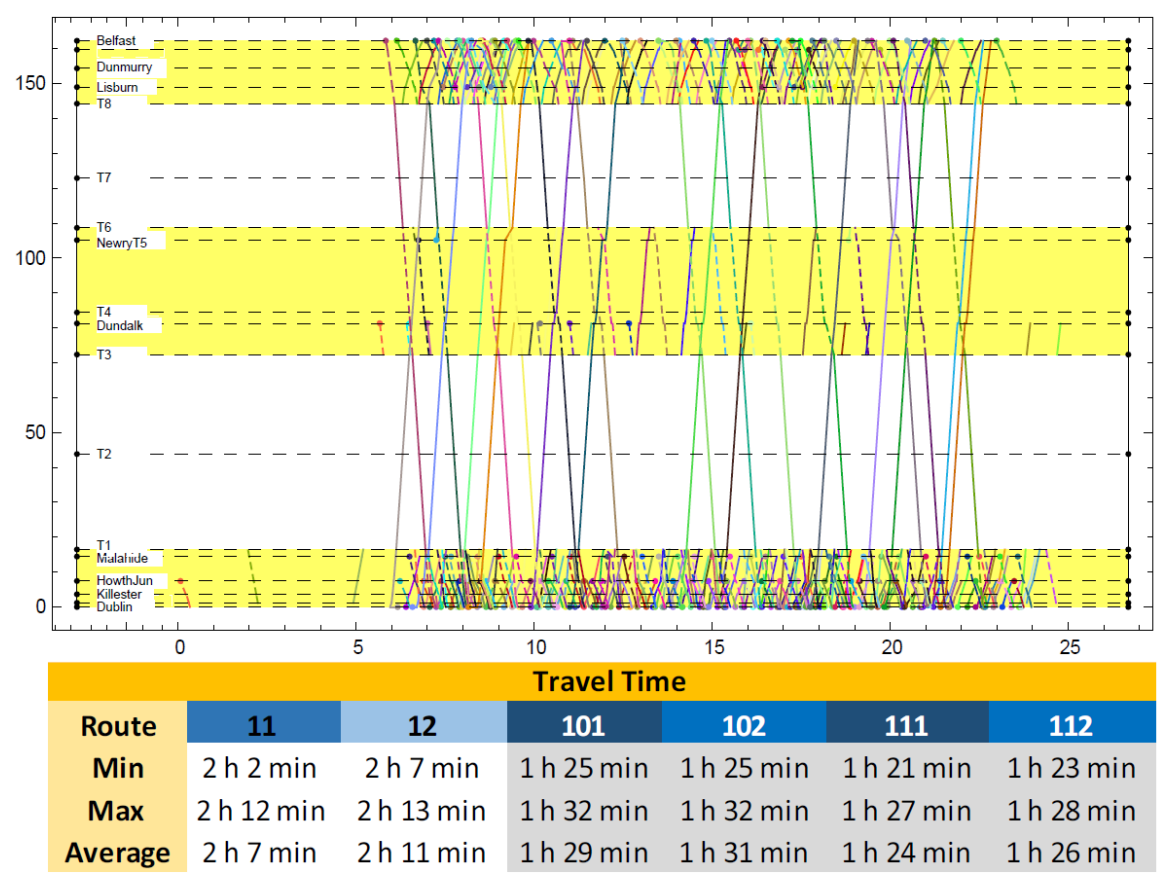

Figure 4 Resulting timetable for 32 daily services showing in yellow color the doubletrack segments and minimum, maximum and average travel times.

The new segments are designed to accept trains with a range of speed between $130 \mathrm{~km} / \mathrm{h}$ and the future high speed $250 \mathrm{~km} / \mathrm{h}$. The unit costs per kilometer of the segments in both singleand double-track, are shown in the right plot of Figure 2.

This proposal is analyzed considering 16+18 services between Dublin and Belfast and the resulting timetables are given in Figure 4, where the shadowed segments correspond to double-track segments. The first conclusion that can be drawn from the optimization is that all new segments should be constructed as single track segments. As a consequence of our analysis, our final proposal consists of constructing the new four segments as single track segments, The proposed line has $161 \mathrm{~km}$, contains $\$ 4 \$$ single track segments $(91.5 \mathrm{~km})$, costs $€ 360.64 \mathrm{M}$. and leads to travel times below 1 hour 30 minutes between Dublin and Belfast, which implies a more than 40 minutes reduction.

\subsection{The Santiago-Valaparaíso/Viña del Mar line}

To connect Santiago with the Valaparaíso/Viña del Mar area we propose a line of $\$ 87.4 \$$ $\mathrm{km}$. connecting the Arturo Merino Benítez airport and El Salto station in Viña del Mar, close to the metro station in order to facilitate the access to the metropolitan area by public transportation and the access of freight trains to the port using the metro infrastructure. The 
line runs following the terrain profile as close as possible. However, it is necessary to drill two tunnels of 13.6 and $5 \mathrm{~km}$, respectively, which are shown in the longitudinal profile of Figure 5. The remaining slopes are resolved by cuttings, embankments and some viaducts.

For the study of the line the 7 segments in Figure 5 have been considered, where their lengths and construction costs in both single and double track are shown. The segments were chosen with very similar length to facilitate the optimization program to choose those that should go in single and double track to reduce construction and maintenance costs.
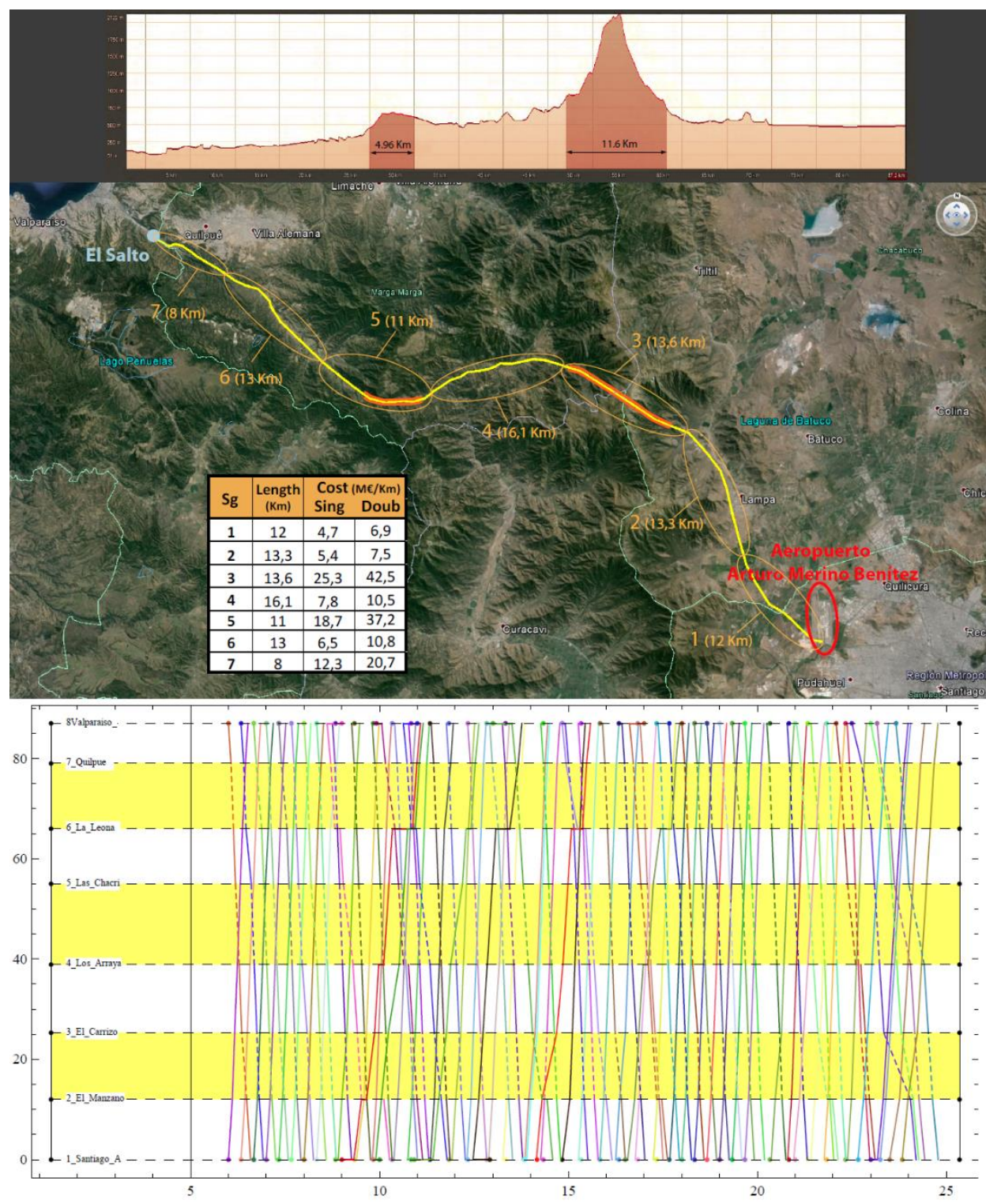

Figure 5 Upper plot: Trace of the Santiago-Valparaíso/Viña del Mar line showing the longitudinal profile and the location of the two tunnels. Lower plot: Proposed timetable, for 76 passenger and 24 freight daily trains.

A mixed line for passenger and freight trains was considered. The maximum service speeds have been $200 \mathrm{~km} / \mathrm{h}$ for passenger trains and $120 \mathrm{~km} / \mathrm{h}$ for freight trains. To ensure safe entrances and exits of trains in different segments times of 3 to 4 minutes for passengers and 
goods, respectively, have been considered. Only two paths: Santiago-El Salto and vice versa have been studied with demands of 1 train every 20 minutes at peak (6: 00-8: 20 and 17: 2020: 20) hours, and every 30 minutes during peak hours (8: 20-17: 20 20: 20-22: 20). This will involve a total of 38 passenger trains each way and 24 freight trains (12 in each direction) for driving in valley hours and at the end of the day. Finally, five night hours have been reserved for line maintenance.

The result of the optimization program leads to four single track segments, corresponding to the two tunnel sections and the two ends, and three double track segments. The resulting approximate cost is $€ 1084 \mathrm{M}$., while the cost two-way would have been $€ 1700 \mathrm{M}$., representing a saving constructive $36.2 \%$. The resulting travel time was 30 minutes.

\section{CONCLUSIONS.}

The most important conclusions derived from this work are:

- Apart from the usual double-track solution to high speed railway lines, the ADST provides an interesting alternative, which with an important cost reduction (up to $40 \%$ ) produces practically the same travel times.

- The combination of existing conventional lines together with high speed tracks of new construction provides a very interesting solution to reduce travel times at a very low cost (up to one tenth of the cost of double-track lines) and without excessive deterioration of travel times.

- The examples of the Palencia-Santander, the Dublin-Belfast and the SantiagoValparaíso-Viña del Mar lines show how these alternatives can be adapted to very different real situations and the important cost reduction produced.

\section{REFERENCES}

CAPRARA, A., FISCHETTI, M., and TOTH, P. (2002). Modeling and solving the train timetabling problem. Operations Research, 50:851-861.

CAPRARA, A., KROON, L., MONACI, M., PEETERS, M., and TOTH, P. (2007). Passenger railway optimization. volume 14, chapter 3, page 129187. Elsevier.

CAREY, M. (1994). A model and strategy for train pathing with choice of lines, platforms and routes. Transportation Research Part B, 28(5):333-353.

CAREY, M. and CRAWFORD, I. (2007). Scheduling trains on a network of busy complex stations. Transportation Research Part B, 41(2):159-178.

CAREY, M. and LOCKWOOD, D. (1995). A model, algorithms and strategy for train pathing. Journal of the Operational Research Society, 46(8):988-1005.

CASTILlO, E., CALVIÑO, A., GRANDE, Z., SÁNCHEZ-CAMBRONERO, S., 
GALLEGO, I., RIVAS. A., and MENÉNDEZ, J. M. (2016a). A Markovian-Bayesian network for risk analysis of high speed and conventional railway lines integrating human errors. Computer Aided Civil and Infrastructure Engineering, 31:193-218.

CASTILlO, E., GALLEGO, I., SÁNCHEZ-CAMBRONERO, S., MENÉNDEZ, J. M., RIVAS, A., NOGAL, M., and GRANDE, Z. (2015a). An alternate double-single track proposal for high speed peripheral railway lines. Computer Aided Civil and Infrastructure Engineering, 30:181-201.

CASTILlO, E., GALlEGO, I., UREÑA, J., and CORONADO, J. (2009). Timetabling optimization of a single railways track line with sensitivity analysis. TOP, 17(2):256-287.

CASTILlO, E., GALLEGO, I., UREÑA, J., and CORONADO, J. (2011). Timetabling optimization of a mixed double and single-tracked railway network. Applied Mathematical Modelling, pages 859-878.

CASTILLO, E., GRANDE, Z., and CALVIÑO, A. (2016c). Bayesian network based probabilistic safety analysis for railway lines. Computer Aided Civil and Infrastructure Engineering, in press.

CASTILlO, E., GRANDE, Z., MORAGA, P., and SÁNCHEZ-VIZCAÍNO, J. (2016b). A time partitioning tool for railway line design and timetable scheduling and for re-scheduling due to disruptions. Computer Aided Civil and Infrastructure Engineering, DOI: $10.1111 /$ mice.12194.

CORDEAU, J. F., TOTH, P., and VIGO, D. (1998). A survey of optimization models for train routing and scheduling. Transportation Science, 32(4):380-404.

D'ARIANO, A., PACCIARELLI, D., and PRANZO, M. (2007a). A branch and bound algorithm for scheduling trains in a railway network. European Journal of Operational Research, 183(2):643-657.

D'ARIANO, A. and PRANZO, M. (2004). A real time train dispatching system based on blocking time theory. 8th TRAIL 8th Annual Congress 2004, A World of Transport, Infrastructure and Logistics, pages 129-152, Delft. DUP Science.

HIGGINS, A., KOZAN, E., and FERREIRA, L. (1996). Optimal scheduling of trains on a single line track. Transportation Research Part B, 30(2):147-161.

JIA, L. M. and ZHANG, X. D. (1993). Distributed intelligent railway traffic control based on fuzzy decision making. Fuzzy Sets and Systems, 62(3):255-265.

KRAAY, D. R. and HARKER, P. T. (1995). Real-time scheduling of freight railroads. Transportation Research Part B, 29(3):213-229.

PACHL, J. (2014). Railway Timetabling and Operations. Analysis - Modelling Optimisation - Simulation - Performance Evaluation, chapter Timetable Design Principles, pages 23-24. Eurailpress, Hamburg.

SAHIN, I. (1999). Railway traffic control and train scheduling based on inter-train conflict management. Transportation Research Part B, 33(7):511-534. 